\title{
Enhancement of Solubility and Bioavailability of Candesartan Cilexetil using Natural P-Glycoprotein Inhibitors
}

\author{
Noor Ahmad Zulal and PK Lakshmi* \\ G Pulla Reddy College of Pharmacy, Mehdipatnam, Hyderabad, AP, India 500028
}

*For correspondence: Email: drlakshmisuresh@gmail.com

\begin{abstract}
Purpose: To enhance the otherwise poor solubility and bioavailability of candesartan cilexetil (CDS). Methods: This study involved enhancing drug solubility by various solid dispersion (SD) methods. The drug: carrier ratio was as follows: for urea (1:2, 1:4 and 1:6; for polyethylene glycol 6000 (PEG, 1:2 and 1:4, 1:8); and mannitol (1:2, 1:4 and 1:6. Piperin and quercetin (natural P-glycoprotein inhibitors) were used as bioavailability enhancers. Bioavailability stdies were carried out in a rat model with the SDs formulated in a suspension form and administered by the oral route.

Results: All the carriers enhanced drug dissolution in water 2 to 4-fold depending on drug/carrier ratio. Release kinetics from solid dispersions made with mannitol showed zero order drug release. Urea and PEG 6000-based solid dispersions showed 1st order drug release kinetics. FTIR studies confirmed transformation to an amorphous form of CDS in mannitol solid dispersion; this was buttressed by release kinetic studies. Bioavailability of the drug in the animals was enhanced by 27 and $68 \%$ when quercetine and piperine, respectively, were incorporated.

Conclusion: Formation of solid dispersion enhances the solubility and bioavailability of CDS when natural P-glycoprotein inhibitors such as piperin and quercetin are incorporated as enhancers.
\end{abstract}

Keywords: Solid dispersion, Candesartan, Cilexetil, Bioavailability, P-Glycoprotein, Piperin, Quercetin

Tropical Journal of Pharmaceutical Research is indexed by Science Citation Index (SciSearch), Scopus, International Pharmaceutical Abstract, Chemical Abstracts, Embase, Index Copernicus, EBSCO, African Index Medicus, JournalSeek, Journal Citation Reports/Science Edition, Directory of Open Access Journals (DOAJ), African Journal Online, Bioline International, Open-J-Gate and Pharmacy Abstracts

\section{INTRODUCTION}

Candesartan cilexetil (CDS), which is an angiotensin II receptor antagonist, is a prodrug that releases candesartan during absorption. CDS was approved by the US Food and Drug Administration (FDA) in 1998 and patented under the name of 'Tab Atacand' [1]. It has the highest affinity for AT1 receptor, where it suppresses the maximal response to angiotensin compared to any other angiotensin II receptor antagonist [2]. The solubility of CDS in water is lower than $5 x$ $10^{-5} \mathrm{~g} /$ /iter and while its bioavailability in solution form is between 15 and $40 \%[18,19]$.
Researchers have tried different methods [3] to enhance its solubility and bioavailability. CDS undergoes passive absorption, and Pglycoprotein efflux transportation decreases its bioavailability. This has been shown in a study on the transport characteristics [4], intestinal absorptive characteristics and efflux mechanisms (P-gp transportation) in human intestinal Caco-2 cell line. Additionally, the inhibitory effects of angiotensin II type 1 receptor blockers (ARBs) on P-glycoprotein (P-gp) were examined on vectorial transport of digoxin [5]. The enhancement of bioavailability with natural 
compounds from medicinal plants depends on mechanisms suxg as P-gp inhibition or nonspecific mechanisms promoting rapid absorption of drugs [6]. CDS is sensitive to $\mathrm{pH}$, light and pressure which cause hydrolysis, disesterification [7] and crystalline changes [8].

The aim of this study was to enhance CDS solubility by achieving a stable amorphous or molecular form of CDS [9] and also enhance its bioavailability with the aid of natural $\mathrm{P}$ glycoprotein inhibitors $[5,10,11]$.

\section{EXPERIMENTAL}

\section{Materials}

Candesartan Cilexetil BP was received as a gift from Dr. Reddy Laboratories Ltd, Hyderabad, India. Polyethylene glycol (PEG) 6000, mannitol, urea, piperine, quercetin, and microcrystalline cellulose were procured from Sigma Aldrich, Mumbai. All the chemicals used for chromatographic analysis were of high performance liquid chromatography (HPLC) grade. All the other chemicals and solvents used were of analytical grade.

\section{Preparation of physical mixture}

The physical mixtures (PM) of CDS, with all the carriers were prepared by mixing the required amount of drug and the carriers in different drug: carrier ratios (for PEG 6000, 1:2, 1:4 and 1:8; for urea, 1:2, 1:4 and 1:6; for mannitol, 1:2, 1:5 and $1: 8)$ in a glass mortar for $5 \mathrm{~min}$. They were sieved through \# 60 mesh (250 micron) and stored in a calcium chloride desiccator until used.

\section{Preparation of solid dispersions of candesartan cilexetil (CDSSDs)}

CDSSDs were prepared based on drug: carrier ratios of 1:2, 1:5 and 1:8 for mannitol as carrier (co-evaporation method) [12], 1:2, 1:4 and 1:8 for PEG 6000 (melt-fusion) [13], and 1:2, 1:4 and 1:6 for urea as carrier (melting method by mixing of melted drug and carrier).

\section{Assay of total drug content}

Known amounts of the drug/carrier (8 $\mathrm{mg}$ drug equivalent) binary systems (SDs or PMs) were dissolved in $10 \mathrm{ml}$ of methanol using a vortex mixer. This was appropriately diluted with methanol and drug content evaluated spectrophotometrically (UV- Visible-double beam spectrophotometer, Chemito Instrument Pvt Ltd, India) at $268.2 \mathrm{~nm}$. Drug content was compared with the theoretical value. The experiments were done in triplicate and the mean values recorded.

\section{Solubility studies}

The dynamic solubility of Candesartan Cilexetil Solid Dispersion (CDSSD) was determined by adding an excess of solid ( $5 \mathrm{mg}$ ) to $5 \mathrm{ml}$ of water and the tubes were vortexed at $300 \mathrm{rpm}$ for 10 minutes. Aliquots of samples were withdrawn, filtered, and analyzed for drug content by UV spectroscopy at $268.2 \mathrm{~nm}$.

\section{Dissolution studies}

Dissolution studies on pure CDS, physical mixture and solid dispersions were carried out using US Pharmacopoeia type I dissolution apparatus (Electrolab pvt. Ltd India). The dissolution medium was $900 \mathrm{ml}$ of $\mathrm{pH} 6.5$ phosphate buffer, containing $0.35 \%$ Tween 20 at $37 \pm 0.5{ }^{\circ} \mathrm{C}$. The stirring speed was $100 \mathrm{rpm}$. Eight (8) $\mathrm{mg}$ equivalent of CDS of solid dispersion in powder form was placed in the basket. A $5.0 \mathrm{ml}$ sample solution was withdrawn at appropriate time intervals and filtered. An equal volume of fresh dissolution medium was immediately replacing the withdrawn sample. The concentration of CDS in the samples was analysed spectrophotometrically at $268.2 \mathrm{~nm}$. The experiments were carried out in triplicate. The mean concentration of the drug was plotted against time. The release data were subjected to first order, zero order, Higuchi and KorsemeyerPeppas models to ascertain model-dependent kinetics of release.

\section{Fourier transform infra-red (FTIR) compatibility studies}

Fourier Transform Infra-red (FTIR) (Shimadzu Corporation Japan) spectra of pure drug or carrier, physical mixture and solid dispersion were recorded in the range $400-4000 \mathrm{~cm}^{-1}$ at room temperature.

\section{Preformulation studies}

The powder blend was analyzed for bulk density, tapped density, Hausner's ratio, compressibility index, and angle of repose [20].

\section{Bioavailability studies}

For the quantification of an active form of CDS in blood, the spiking technique was followed. A known concentration of CDS was added to the Rats' blood and CDS in the blood was evaluated by HPLC method [13]. As CDS (prodrug) is converted to candesartan in the blood, the 
amount of candesartan was subtracted from the known amount of CDS added to blood initially, and hence the total amount of candesartan (active drug) was determined in the blood. This was correlated with the peak to peak area obtained from HPLC analysis of the same sample analyzed for candesartan.

Bioavailability studies were carried out in rats, after approval by the institutional ethics committee of $G$. Pulla Reddy College of Pharmacy, India. Inbred adult albino Wister rats, weighing 90 - $120 \mathrm{~g}$ maintained in standard laboratory conditions of temperature, humidity, $12 \mathrm{~h} / 12 \mathrm{~h}$ light and dark cycles, normal diet (M/S. Lipton India Ltd) and water ad libitum, were randomly divided into 3 groups of six animals each ( 3 female and 3 male). The females were nulliparous and not pregnant.

Candesartan cilexetil/PEG 6000 solid dispersion $(1: 4,1 \mathrm{mg} / \mathrm{kg})$ was selected as a reference. Group 1 was administered the pure drug. The second group was the reference drug with quercetin $(10 \mathrm{mg} / \mathrm{kg})$ as a PGP inhibitor. The third group was the reference drug with piperine $(10 \mathrm{mg} / \mathrm{kg})$ as a Pgp modulator. Each group was divided into two subgroups of females and males (Table 2).

Both male and female rats were administered the suspension form of test and reference orally by oral tube and blood samples were collected by retro-orbital method. Samples were collected in $2: 45$ th, 5th, 7th, 27th h. Samples were kept at $17^{\circ} \mathrm{C}$ until further studies. The frozen samples were thawed at room temperature and centrifuged at $6000 \mathrm{rpm}$ prior to further studies.

\section{Statistical analysis}

Statistical analysis was performed on the dissolution data obtained from dissolution data using Microsoft Excel 2007 and the pharmacokinetic parameters data obtained from subject were calculated manually.

\section{RESULTS}

\section{Drug content}

Drug content of solid dispersions made with PEG 6000 showed $100.0 \pm 3.5 \%$, while for those made with mannitol and urea it was $94.0 \pm 3.0$, and $84.0 \pm 8.5 \%$, respectively.

\section{Drug solubility}

The solubility of CDSSD increased linearly with increase in concentration of the carriers. The rank order of solubility was PEG 6000 (4.3 fold) > mannitol $(2.5$ fold $)>$ urea $(1.8$ fold $)>$ physical mixtures (for all carriers).

\section{In vitro drug dissolution}

Drug release from physical mixture was greater than that from the pure drug but lower than that of the solid dispersions, [14]. Physical mixture with mannitol, and PEG did not show much increase in the solubility of CDS (Table 1). The rank order for the various carriers was PEG 6000 (4.3 fold) $>$ mannitol $(2.5$ fold $) \mathrm{I}>$ urea $(1.8$ fold $)>$ physical mixtures (for all carriers).

The model dependent methods given in (Table 2) and profiles generated from zero order, first order, Higuchi and Korsmeyer-Peppas derived data suggest urea and PEG SDs followed 1st order kinetics while mannitol SD followed zero order kinetics.

All the other SDs followed Higuchi release model, suggesting that drug release mechanism is by diffusion. The diffusion exponent, 'n', being $<0.5$, suggests Fickian release.

Table 1: Dissolution of selected candesartan cilexetil solid dispersion and physical mixtures

\begin{tabular}{lccccccc}
\hline $\begin{array}{l}\text { Time } \\
\text { (min) }\end{array}$ & $\begin{array}{c}\text { Purecandesartan } \\
\text { cilexetil (CDS) }\end{array}$ & \multicolumn{2}{c}{$\begin{array}{c}\text { CDS: mannitol } \\
(\mathbf{1 : 5 )}\end{array}$} & \multicolumn{2}{c}{ CDS: urea (1:6) } & \multicolumn{2}{c}{ CDS: PEG 6000 (1:4) } \\
\cline { 3 - 8 } & & PM & SD & PM & SD & PM & SD \\
\hline 5 & 72.60 & 77.48 & 97.96 & 82.3 & 82.3 & 62.6 & 65.75 \\
10 & 76.85 & 78.79 & 96.14 & 86.25 & 86.25 & 63.82 & 91.64 \\
15 & 79.41 & 80.1 & 100.4 & 93.73 & 95.49 & 65.49 & 96.43 \\
30 & 86.68 & 91.48 & 102.4 & 97.75 & 97.76 & 78.54 & 97.52 \\
45 & 87.15 & 93.29 & 100.6 & 98.29 & 100.5 & 80.28 & 100.5 \\
60 & 89.76 & 95.55 & 104 & 98.82 & 101 & 82.03 & 101.8 \\
\hline
\end{tabular}




\section{Crystallinity}

The essential features of the three solid dispersion spectra was the strong absorption band at $1755.10-1716 \mathrm{~cm}^{-1}$ assigned to the carbonyl stretching vibration. The absorption band observed at $1716.53 \mathrm{~cm}^{-1}$ in the case of CDS-mannitol solid dispersion was shifted to $1730.03 \mathrm{~cm}^{-1}$, although another carbonyl absorption band was commonly recognized at the same position.

\section{Bioavailability CDS solid dispersion containing pgp inhibitors}

The present study was designed to compare single dose bioavailability studies of optimized CDS solid dispersion (PEG-6000) with or without PGP inhibitors in rat. Serum drug concentration of candesartan after oral administration is presented in (Table 3 and Fig 1).

Table 2: Release kinetics of candesartan cilexetil containing various carriers

\begin{tabular}{|c|c|c|c|c|c|c|c|c|c|c|c|c|}
\hline \multirow[t]{2}{*}{ Formulation } & \multirow[t]{2}{*}{ Method } & \multirow[t]{2}{*}{ Ratio } & \multicolumn{2}{|c|}{ Zero order } & \multicolumn{2}{|c|}{ First Order } & \multicolumn{2}{|c|}{ Higuchi } & \multicolumn{3}{|c|}{ Peppas } & \multirow{2}{*}{$\begin{array}{l}\text { Release } \\
\text { type }\end{array}$} \\
\hline & & & $\mathbf{R}^{2}$ & $\mathbf{K}$ & $\mathbf{R}^{2}$ & $\mathbf{K}$ & $\mathbf{R}^{2}$ & $\mathrm{~K}$ & $\mathbf{R}^{2}$ & $\mathbf{K}$ & $\mathbf{n}$ & \\
\hline CDS: mannitol & Co-evaporation & $1: 5$ & 0.679 & 6.545 & 0.420 & -0.444 & 0.706 & 8.691 & 0.693 & 2.013 & 0.025 & Fickian release \\
\hline CDS: urea & Melting & $1: 6$ & 0.753 & 18.74 & 0.881 & -1.416 & 0.853 & 25.99 & 0.922 & 2.012 & 0.085 & Fickian release \\
\hline $\begin{array}{l}\text { CDS: PEG } \\
6000\end{array}$ & Fusion & $1: 4$ & 0.489 & 26.06 & 0.788 & -1.447 & 0.604 & 37.71 & 0.702 & 2.030 & 0.144 & Fickian release \\
\hline
\end{tabular}

Table 3: Pharmacokinetic parameters of candesartan following single dose (12 $\mathrm{mg})$ oral administration

\begin{tabular}{|c|c|c|c|c|c|}
\hline Formulation & Cmax ng/ ml & $T_{1 / 2}(h)$ & $\mathrm{AUC}_{0-\mathrm{t}} \mathrm{ng} \mathrm{h} / \mathrm{ml}$ & $A U C_{0-\infty}(\mathrm{ng} \mathrm{h} / \mathrm{ml}$ & $K_{E}(h)$ \\
\hline CDSSD (female) & 134 & 1.809 & 859.25 & 864.211 & 0.383 \\
\hline CDSSD (male) & 150 & 2.092 & 1031.3 & 1037.64 & 0.331 \\
\hline CDSSDP (female) & 212 & 2.784 & 1361.125 & 1370.767 & 0.2489 \\
\hline CDSSDP (male) & 252 & 2.915 & 1637.065 & 1652.07 & 0.2377 \\
\hline CDSSDQ (female) & 171 & 3.726 & 1264.065 & 1304.39 & 0.0808 \\
\hline CDSSDQ (male) & 175 & 3.72 & 1251.875 & 1277.598 & 0.1866 \\
\hline
\end{tabular}

Note: $C D S S D$ = candesartan solid dispersion with PEG 6000; CDSSDP = candesartan solid dispersion with PEG 6000 and piperin; $C D S S D Q=$ candesartan solid dispersion with PEG 6000 and quercetin

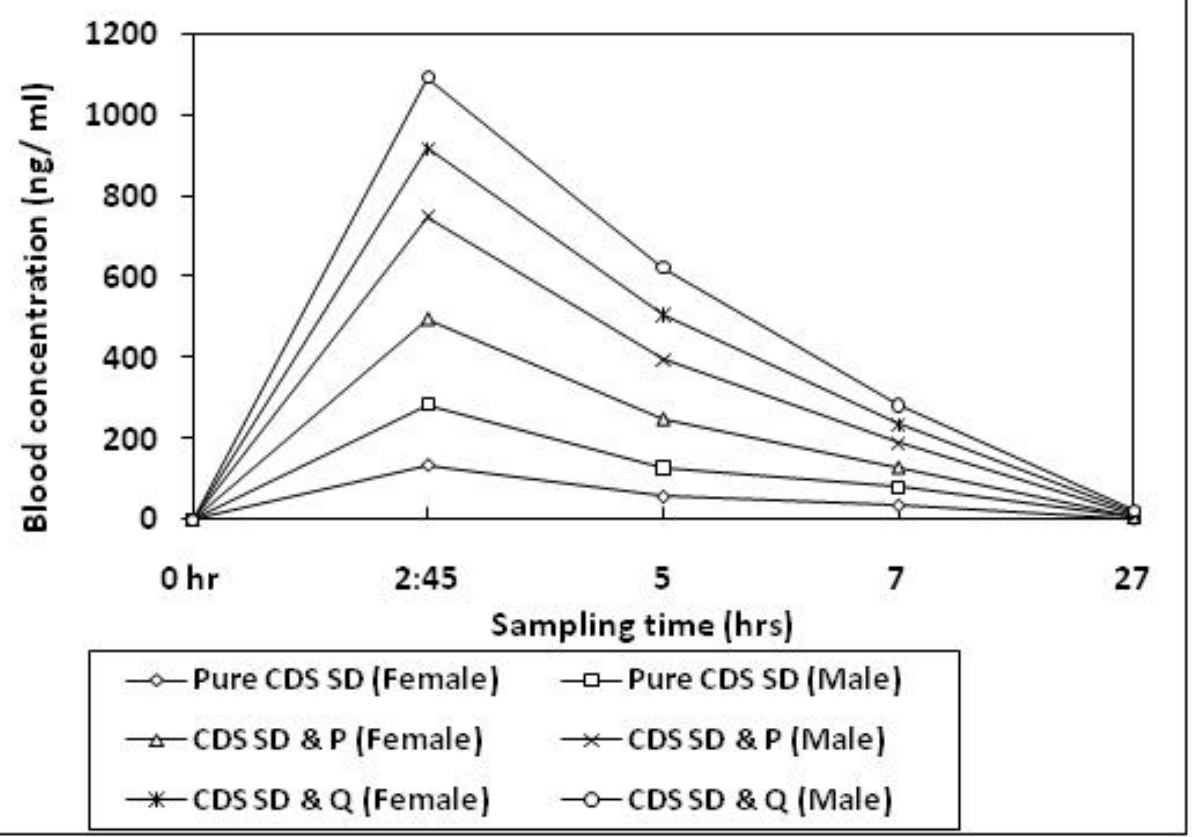

Fig 1: Plasma drug concentration of candesartan after single dose (250 $\mu$ g equivalent) oral administration 
The pharmacokinetic data indicate enhanced bioavailability with marked improvement in absorption rate and extent compared to the CDSSD. The mean area under the serum candesartan curve (AUC) differed significantly from CDSSD/quercetin (CDSSDQ) or candesartan cilexetil/piperin solid dispersion (CDSSDP) and CDSSD. A mean of 58 and $68 \%$ increase in serum candesartan AUC were observed for CDSSDP female and male groups, compared to CDSSD female and male groups respectively. A mean of 27.5 and $17 \%$ increase in serum candesartan AUC was observed in CDSSDQ female and male groups compared with CDSSD female and male groups, respectively. There was a little increase in candesartan $t_{1 / 2}$, which may be responsible for the decrease in the rate of drug metabolism in the liver due to quercetin's inhibitory effect on CYP3A4. Other pharmacokinetic parameters did not change significantly (Table 3 ).

\section{DISCUSSION}

PEG 6000 gave better solubility and dissolution than the other carriers hence it was chosen as the desired carrier and selected for in vivo study. The toxic effect of urea is a drawback for its use as a carrier. Hence urea was not selected for further study.

The differences in the spectra of CDS between physical mixture and the solid dispersion suggest that the conformation of a cyclohexcyloxy carbonyloxy ethyl group of CDS in physical mixture is different from that in the solid dispersion. According to Hirokazu et al [8] the amorphous of CDS exhibited a broader IR spectrum than the spectra of crystalline forms I and II. The absorption band assigned to the carbonyl stretching vibration was shifted to the middle position $\left(1728 \mathrm{~cm}^{-1}\right)$ of form I $\left(1717 \mathrm{~cm}^{-1}\right)$ and form II $\left(1736 \mathrm{~cm}^{-1}\right)$, indicating the existence of the amorphous form of CDS in CDS-mannitol solid dispersion. In the case of CDS-PEG solid dispersion, the peak at $1724.24 \mathrm{~cm}^{-1}$ did not show much difference and thus indicates low level of amorphous CDS. The absorption band at $1716.53 \mathrm{~cm}^{-1}$ for CDS-urea solid dispersion was not seen because of the overlap between urea and CDS carbonyl group and therefore it requires further study.

In order to understand the mechanism and kinetics of drug release, the in vitro release data were fitted to various kinetic models to ascertain their release mechanisms. The best-fit model was selected based on the highest determination coefficient, smaller difference between each fitted and actual data and the smaller value of the residual mean square.

Bioavailability enhancement by quercetin was less compared to piperin. Many studies have shown the effect of quercetin. In the present study, $10 \mathrm{mg} / \mathrm{kg}$ concentration of quercetin and piperine were used and they showed significant inhibition of intestinal P-gp in rats and enhanced the bioavailability of candesartan cilexetil. Though a little increase in $t_{1 / 2}$ was observed with quercetin but it requires further study to be done. Promising results were obtained with formulations of PEG solid dispersion containing piperin, a natural P-gp inhibitor as bioavailability enhancer. Despite the fact that the results obtained are promising, further studies are required to optimize the concentration of piperine or quercetin and to formulate them onto herbosomes or use them as a dietary supplement.

The mechanism of increased bioavailability of CDSSDP may be due to various reasons. Piperine, an alkaloid (I-peperoyl piperidine), has been previously evaluated for its ability to increase serum response and lengthen serum half-life of drugs in both experimental animals and human volunteers These studies suggest that orally administered piperine may significantly increase serum levels, and lengthen the serum half-lives of chemically diverse groups of naturally occurring and synthetic drugs $[15,16]$. Bioavailability enhancement with piperine may be due to PGP inhibitory effects and the increased micelle formation, hyperemia [17], and epithelial cell wall modification due to the lipophilic nature of piperine, or an increase in the bioenergetics processes of the gastrointestinal epithelium due to the thermogenic properties of piperine [16]. It is also possible that the localized thermogenic effect of piperin on epithelial cells may increase the uptake of drugs from the gut.

\section{CONCLUSION}

PEG 6000 was the most efficient solubilising carrier, improving water solubility 4-fold. The bioavailability of candesartan cilexetil was enhanced 22 and $63 \%$ by quercetin and piperine, respectively.

\section{REFERENCES}

1. Office of Generic Drugs [Internet]. Approved Drug Products; [Updated 2009 December 31; cited 2010 April 24]. available from: http://www.fda.gov/down loads/Drugs/DevelopmentApprovalProcess/UCM071 436.pdf 
2. Laurence B, John L, Keith P. Goodman \& Gilman's the Pharmacological Basis of Therapeutics. 10th Ed. United States: McGraw-Hill; 2006. 832,894,911 p.

3. Vijaykumar $N$, Raviraj $P$, Vobalaboina V, Harisudhan $T$. Development and characterization of solid oral dosage form incorporating candesartan nanoparticles. J Pharmaceutical Dev. \& Tech. 2009; 14 (3): 290-298.

4. Lingjie Z, Chen $X, G u \quad Y$, Liang J. Transport characteristics of Candesartan in Human Intestinal Caco-2 Cell Line. Biopharm. Drug Dispos 2009; 30: 259-264

5. Emi K, Nakai D, Okudaira N, Okazaki O. Interaction of angiotensin II type 1 receptor blockers with P-gp substrates in Caco-2 cells and hMDR1-expressing membranes. Life Sci 2010 Jan 2; 86(1-2): 52-8.

6. Brahama NS, Kwon HK. Drug Delivery: Oral Route. In: James Swarbrick, editor. Encyclopedia of pharmaceutical technology. 3rd edition. USA: Informa Health Care; 2007. p. 1242-1265.

7. Nero F, Sebastian D, Rosa MA, Wolfgang W. Hydrolysis and transesterification reactions of candesartan cilexetil observed during the solid phase extraction procedure. J Chromatography 2007; B (855): 134 138.

8. Hirokazu M, Taro E, Koji N, Toshio E, Kazumichi S, Nobuo N. Solid-state characterization of Candesartan Cilexetil (TCV-116): Crystal Structure and Molecular Mobility. Chem Pharm Bull 1999; 47(2): 182-186.

9. Frank, G. Stabilized amorphous candesartan cilexetil compositions for oral administration. EP 1997479 A1 (European patent application Bulletin 2008/49; Date of application 03. 12. 2008)

10. Sang CS, Jun SC, Xiuguo L. Enhanced bioavailability of tamoxifen after oral administration of tamoxifen with quercetin in rats. Int. J Pharmaceutics 2006; 313: 144-149.

11. Tripta B, Manu J, Roop KK, Sushama T. Emerging Significance of Flavonoids as P-Glycoprotein
Inhibitors in Cancer Chemotherapy. J Pharm Pharmaceut Sci 2009; 12 (1): 46-78.

12. Rajesh $K$, Suresh $N$, Shrinivas $B$, Bhanudas $K$. Preparation, physicochemical characterization, dissolution and formulation studies of irbesartan cyclodextrin inclusion complexes: Comparison between $\beta-C D \& H P-\beta-C D$. J pharma Research. 2009; 2(8): 1359-1364.

13. Garima C, Arvind KB. Improved dissolution of a poorly water soluble drug in solid dispersions with polymeric and non-polymeric hydrophilic additives. Acta Pharm 2008; 58: 257-274.

14. Arora SC, Sharma PK, Raghuveer I, Anurag K, Neeraj S, Jagbir G. Development, Characterization and Solubility Study of Solid Dispersion of Cefpodoxime Proxetil by Solvent Evaporation Method. Int. J ChemTech 2010; 2 (2): 1156-1162.

15. Actual CK, Zutshi U, Rao PG. Scientific evidence of the role on Ayurvedic herbals on bioavailability of drugs. J Ethnophann 1981; 4: 229-232.

16. Bar G, Raina RK, Zutshi U, Bedi KL, Johri RK, Sharma SC. The effect of piperine on bioavailability and pharmacokinetics of propranololol and theophylline in healthy volunteers. Eur J Clin Pharmcol 1991; 4 (1): 615-617.

17. Annamalai AR, Manavalan R. Effect of "Trikatu" and its individual components and piperine on gastrointestinal tracts: Trikatu - a bioavailable enhancer. In Drugs 1990; 27(12): 595-604.

18. Israili ZH. Clinical pharmacokinetics of angiotensin II (AT1) receptor blockers in hypertension. J Hum Hypertens 2000; 14(Suppl 1): S73-S86

19. Gleiter $\mathrm{CH}$, Morike KE. Clinical pharmacokinetics of candesartan. Clin Pharmacokinet 2002; 41: 7-17.

20. Babu GV, Kumar NR, Himasankar K, Seshasayana A, Murthy KV. Nimesulide-modified gum karaya solid mixtures: Preparation, characterization and formulation development. Drug Dev Ind Pharm 2003; 29: $855-864$ 